\title{
A WIDE TUNING RANGE CMOS VOLTAGE CONTROLLED OSCILLATOR
}

\author{
Karim Shahbazi and Alireza Hassanzadeh \\ Department of Electrical and Computer Engineering, Shahid Beheshti University, \\ Tehran, Iran
}

\begin{abstract}
In this paper a new wide tuning range CMOS voltage controlled oscillator has been introduced. Two techniques have been used simultaneously to increase the tuning range of a ring oscillator. By combining current control and bulk forward biasing techniques the oscillation frequency can be controlled over a large frequency range with a low phase noise of $-86 \mathrm{dBc} / \mathrm{Hz}$ at $1 \mathrm{MHz}$ offset from $5.8 \mathrm{GHz}$ center frequency. The TSMC 180nm CMOS process with 1.8V supply voltage has been used for the design. The proposed voltage controlled oscillator has $1.73-9.27 \mathrm{GHz}$ frequency range with control voltage of $0-1 \mathrm{~V}$ and consumes $5.17 \mathrm{~mW}$ of power at center frequency oscillation.
\end{abstract}

\section{KEYWORDS}

CMOS VCO, Ring oscillator, Wide tuning range oscillator

\section{INTRODUCTION}

PLL (Phase Locked Loop) has wide range of applications in communication and wireless systems[1]. It can be used for time base generation and synchronization circuits in digital ICs as well as phase detection and demodulation in analog circuits[1]. Figure 1 shows the block diagram of a PLL circuit. The heart of a PLL is voltage controlled oscillator (VCO) that can be implemented using LC or ring oscillators $[2,3]$.

LC oscillators use small value of capacitor and inductor [4] which usually have low quality factor. The low quality factor causes large phase noise and narrow tuning range. Therefore, LC oscillators are mostly used in high phase noise and narrow tuning range applications[5]. Furthermore, large spiral inductors consume a large chip area that is not desirable for integration.

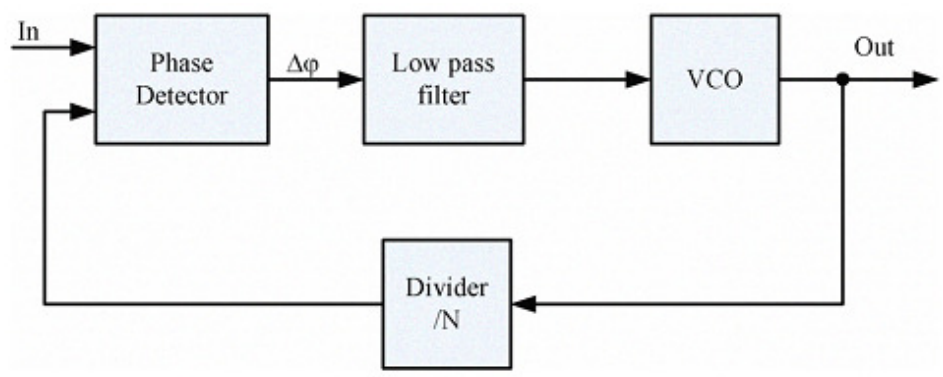

Figure1. A typical PLL circuit block diagram 
Ring voltage controlled oscillators (RVCO) have lower phase noise than LC oscillators and because of the wide tuning range, they are used in PLL circuits. In addition, because of smaller chip area comparing to LC oscillators, it is easier to integrate them in a CMOS technology.

A ring oscillator consists of multiple gain stages (delay cells) in a loop $[4,6]$ as shown in Figure 2. Different delay cells have been compared in terms of different parameters such as tuning range, power dissipation and phase noise. The delay cells can be differential or single-ended units. Differential configuration is more common because of common mode noise rejection capability, but uses larger chip area and consume more power[3]. The challenges in the RVCO design are to achieve linearity of frequency modulation, low voltage and power Consumption, low phase noise and wide frequency range [7].

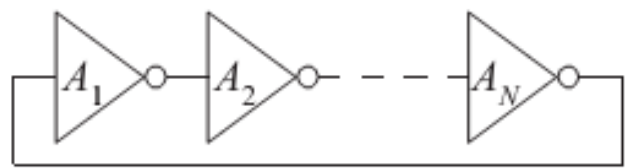

(a)

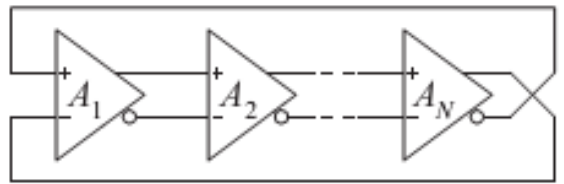

(b)

Figure 2. (a) Single-ended RVCO (b) Differential RVCO

A single-ended oscillator should contain odd number of delay/gain stages with $\pi / \mathrm{n}$ delay value for each stage in a feedback loop[8]. Most reported designs use single ended or differential configuration using current controlled (CC) or voltage controlled (VC) technique as shown in figure $3[4,9]$.

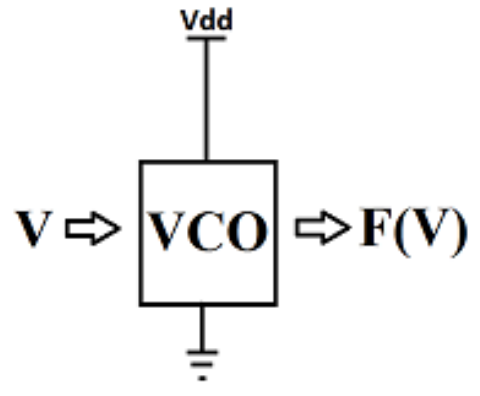

(a)

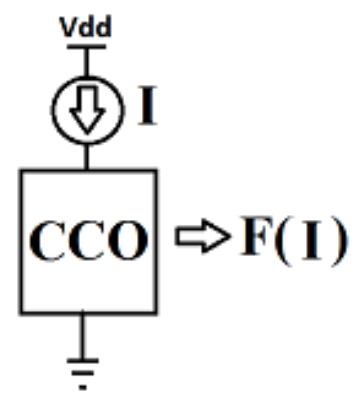

(b)

Figure 3. (a) voltage-controlled oscillator. (b) current-controlled oscillator [9]

Table 1 shows different methods reported for RVCO design in the literature. 
Table1. Summary of techniques used in RVCO design

\begin{tabular}{|c|c|c|c|c|}
\hline \multirow{2}{*}{ REF } & \multicolumn{4}{|c|}{ Technique } \\
\cline { 2 - 5 } & \multicolumn{2}{|c|}{$\begin{array}{c}\text { Single } \\
\text { Ended }\end{array}$} & \multicolumn{2}{c|}{ Differential } \\
\cline { 2 - 5 } & CC & VC & CC & VC \\
\hline$[1]$ & - & - & - & $*$ \\
\hline$[5]$ & - & - & $*$ & - \\
\hline$[10]$ & - & $*$ & - & - \\
\hline$[9]$ & $*$ & - & - & - \\
\hline$[11]$ & - & - & - & $*$ \\
\hline$[12]$ & - & - & - & $*$ \\
\hline
\end{tabular}

In this design the current controlled method with body biasing technique have been used to decrease the threshold voltage $V_{\text {th }}$ and improve the RVCO performance. Single-ended circuit has been simulated to present the concept, even though, the method can be extended to differential pair configuration.

This paper has been structured as follows, section 2 describes RVCO circuit design, transistor sizing and oscillation frequency. Simulation and analysis of the circuit are in section 3. Concluding remarks are at the end.

\section{RVCO DESIGN}

Figure 4 shows one of the methods commonly used for variable frequency implementation in RVCOs. A variable current source is used to control charging current of the node capacitors and therefore the oscillation frequency. By adjusting the current source value the time required for charging and discharging the parasitic capacitance will change and therefore, the frequency of oscillation will change. The larger the current adjustment range, the wider the oscillation frequency can be tuned. A PMOS transistor can be used as a current source which its gate voltage is controlled to change the charging current value. Even though this method provides a variable frequency, the range of adjustment is limited due to the threshold voltage and supply voltage limitations.

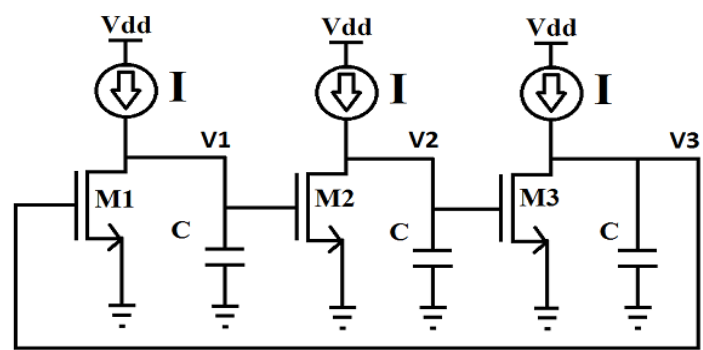

Figure 4. Variable current source for variable oscillation frequency

The method used in this work utilizes the bulk voltage to change the charging current over a wider range besides to gate voltage control. 
A three stage ring oscillator with current control method has been used as the base for the RVCO design. Even though more stages can be used for the RVCO, it will lower the oscillation frequency and increases power dissipation. A variable control voltage has been used to change the current source and so the oscillation frequency. Figure 5 shows one stage of the RVCO that has been employed in the proposed design.

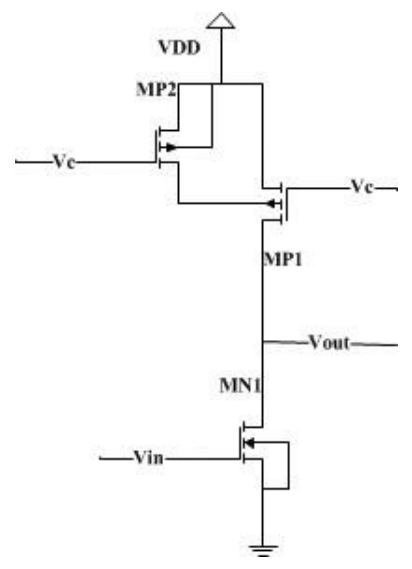

Figure 5. One delay stage of the RVCO

In order to change the current source in a wider range, besides to the gate voltage control, bulk voltage has also been used. The bulk voltage of the PMOS transistor should be controlled in a way that the bulk-source junction remains in reverse or slightly into forward bias. To guarantee this the bulk-source junction will not go into forward bias more than $0.5 \mathrm{~V}$, so the bulk current will remain negligibly low $[5,10]$. An extra transistor PM2 has been used to better control the bulk voltage and reduce loading effects on the control voltage as shown in Figure 5. The proposed 3 -stage RVCO are shown in figure 6.

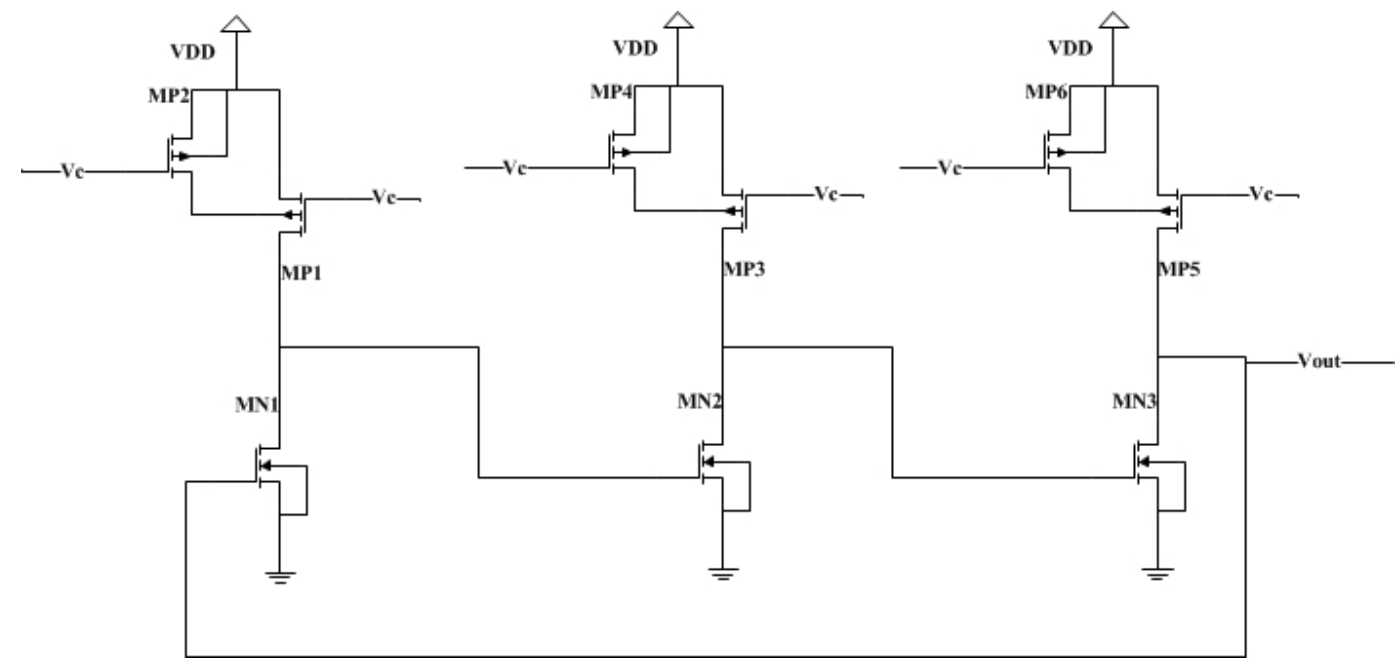

Figure 6. The proposed 3-stage RVCO

\subsection{Transistor Sizing}

In order to have a $50 \%$ duty cycle for the oscillator signal, transistor sizes need to be selected accordingly. Considering Figure 3 and assuming only one NMOS transistor being ON at each 
time slot (T/3), it is concluded that the parasitic capacitors will be charged to about two times the threshold voltage of the NMOS transistor $\left(2 \mathrm{~V}_{\text {thn }}\right)$ [9]. If $\mathrm{M} 1$ is $\mathrm{ON}, \mathrm{C} 1$ will be discharging and $\mathrm{C} 2$ is charging at the same time. When V2 is equal to $\mathrm{V}_{\text {thn }}, \mathrm{M} 3$ will turn $\mathrm{ON}$ and V3 will decrease that causes M1 to turn OFF. Since currents and internal resistance of the current sources are equal, $\mathrm{V} 2$ will charge to $2 \mathrm{~V}_{\mathrm{thn}}$ and the same repeats for all other periods [5].

For the proper operation of the circuit, transistor sizes should be selected carefully. Therefore, the transition point of a delay cell has been selected to be $\mathrm{V}_{\mathrm{T}}$ mid-point of the voltage transfer characteristic (VTC)[13].. At the mid-point of the VTC, NMOS and PMOS transistors will be in saturation and have almost equal currents. From the equality of NMOS and PMOS transistor currents we can write:

$$
\begin{aligned}
& \mathrm{I}_{\mathrm{P}}=\mathrm{I}_{\mathrm{n}} \\
& \frac{1}{2} \mathrm{~K}_{\mathrm{p}}\left(\frac{\mathrm{W}}{\mathrm{L}}\right)_{\mathrm{p}}\left(\mathrm{V}_{\mathrm{DD}}-\mathrm{V}_{\mathrm{T}}-\mathrm{V}_{\mathrm{THP}}\right)^{2}=\frac{1}{2} \mathrm{~K}_{\mathrm{n}}\left(\frac{\mathrm{W}}{\mathrm{L}}\right)_{\mathrm{n}}\left(\mathrm{V}_{\mathrm{GS}}-\mathrm{V}_{\text {TH } 0 \mathrm{n}}\right)^{2}
\end{aligned}
$$

Considering body effect for PMOS transistors:

$$
\left|\mathrm{V}_{\mathrm{thp}}\right|=\left|\mathrm{V}_{\mathrm{th} 0 \mathrm{p}}\right|+\gamma\left(\sqrt{2\left|\phi_{\mathrm{f}}\right|-\mathrm{V}_{\mathrm{sb}}}-\sqrt{\left.2\left|\phi_{\mathrm{f}}\right|\right)}\right.
$$

Since $\mathrm{V}_{\mathrm{GS}}=2 \mathrm{~V}_{\mathrm{thn}}$, NMOS transistors are in saturation and we can use the quadratic equation.

$$
\begin{aligned}
& \sqrt{\frac{\mathrm{K}_{\mathrm{p}}\left(\frac{\mathrm{W}}{\mathrm{L}}\right)_{\mathrm{p}}}{\mathrm{K}_{\mathrm{n}}\left(\frac{\mathrm{W}}{\mathrm{L}}\right)_{\mathrm{n}}}\left(\mathrm{V}_{\mathrm{DD}}-\mathrm{V}_{\mathrm{T}}-\left|\mathrm{V}_{\mathrm{THP}}\right|\right)=\left(2 \mathrm{~V}_{\mathrm{TH} 0 \mathrm{n}}-\mathrm{V}_{\mathrm{TH} 0 \mathrm{n}}\right)} \\
& \sqrt{\frac{\mathrm{K}_{\mathrm{p}}\left(\frac{\mathrm{W}}{\mathrm{L}}\right)_{\mathrm{p}}}{\mathrm{K}_{\mathrm{n}}\left(\frac{\mathrm{W}}{\mathrm{L}}\right)_{\mathrm{n}}}}\left(\mathrm{V}_{\mathrm{DD}}-\mathrm{V}_{\mathrm{T}}-\left|\mathrm{V}_{\mathrm{THP}}\right|\right)=\mathrm{V}_{\mathrm{TH} 0 \mathrm{n}}
\end{aligned}
$$

$$
\sqrt{\frac{\mathrm{K}_{\mathrm{p}}\left(\frac{\mathrm{W}}{\mathrm{L}}\right)_{\mathrm{p}}}{\mathrm{K}_{\mathrm{n}}\left(\frac{\mathrm{W}}{\mathrm{L}}\right)_{\mathrm{n}}}} \mathrm{V}_{\mathrm{T}}=\sqrt{\frac{\mathrm{K}_{\mathrm{p}}\left(\frac{\mathrm{W}}{\mathrm{L}}\right)_{\mathrm{p}}}{\mathrm{K}_{\mathrm{n}}\left(\frac{\mathrm{W}}{\mathrm{L}}\right)_{\mathrm{n}}}}\left(\mathrm{V}_{\mathrm{DD}}-\left|\mathrm{V}_{\mathrm{THP}}\right|\right)-\mathrm{V}_{\mathrm{TH} 0 \mathrm{n}}
$$

$$
V_{T}=\left(V_{D D}-\left|V_{T H P}\right|\right)-\sqrt{\frac{K_{n}\left(\frac{W}{L}\right)_{n}}{K_{p}\left(\frac{W}{L}\right)_{p}}} V_{T H 0 n}
$$


Since $\mathrm{V}_{\mathrm{DD}}=1.8 \mathrm{~V}$, ideally $\mathrm{V}_{\mathrm{thn}}=\left|\mathrm{V}_{\mathrm{THp}}\right|$, therefore, after simplification transistor sizes can be calculated using TSMC $180 \mathrm{~nm}$ technology parameters as follows:

$$
\frac{\mathrm{K}_{\mathrm{n}}\left(\frac{\mathrm{W}}{\mathrm{L}}\right)_{\mathrm{n}}}{\mathrm{K}_{\mathrm{p}}\left(\frac{\mathrm{W}}{\mathrm{L}}\right)_{\mathrm{p}}}=2.56
$$

Since $\mu_{\mathrm{n}}=2.52 \mu_{\mathrm{p}}$, for linear VTC the $\mathrm{W}_{\mathrm{n}}$ should equal to $\mathrm{W}_{\mathrm{p}}$ [13]. For simulation purposes $\mathrm{W}=10 \mu \mathrm{m}$ and $\mathrm{L}=180 \mathrm{~nm}$ have been selected. Figure 7 shows the VTC simulation for the selected sizes and the technology parameters.

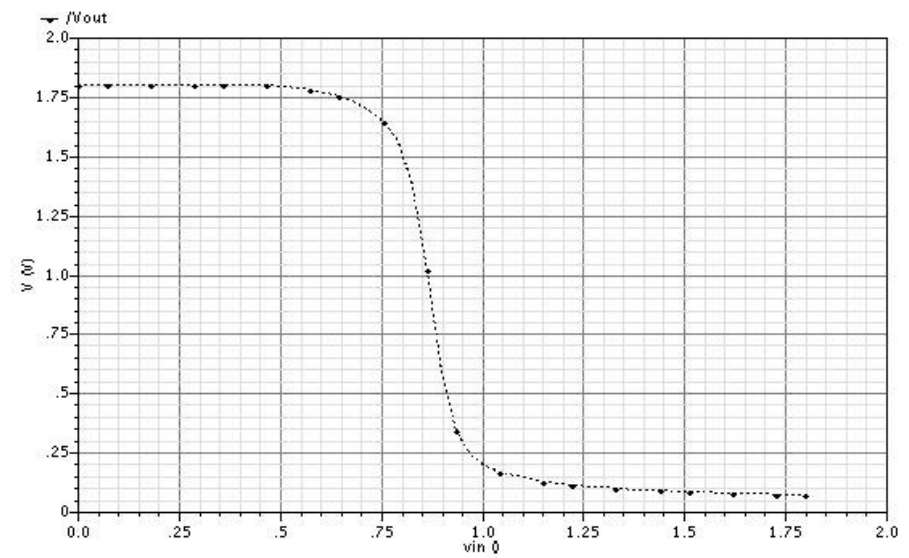

Figure 7. VTC of the proposed delay cell

\subsection{RVCO Oscillation Frequency}

Frequency of the oscillation can be calculated using charging current and stray capacitors. The current source will remain in saturation since the saturation condition will always hold for the PMOS current source. The time delay is equal to the resistance times the capacitor.

$\mathrm{T}_{\text {delay }}=\mathrm{RC}_{\text {load }}$

$\mathrm{T}_{\text {delay }}=\frac{\mathrm{V}_{\mathrm{DSn}}}{\mathrm{I}} \mathrm{C}_{\text {load }}$

Because of the linearity of the VTC, we can assume that capacitor charge and discharge times are equal, therefore:

$$
\begin{aligned}
& \mathrm{f}_{\text {osc }}=\frac{1}{3\left(\mathrm{~T}_{\text {rise }}+\mathrm{T}_{\text {fall }}\right)} \\
& \mathrm{f}_{\text {osc }}=\frac{1}{6 \mathrm{~T}_{\text {delay }}}
\end{aligned}
$$




$$
\begin{aligned}
& \mathrm{f}_{\text {osc }}=\frac{\mathrm{I}}{6 \mathrm{~V}_{\text {DSn }} \mathrm{C}_{\text {load }}} \\
& \mathrm{f}_{\text {osc }}=\frac{1}{6 \mathrm{C}_{\text {load }} \mathrm{V}_{\text {DSn }}}\left(\frac{1}{2} \mathrm{~K}_{\mathrm{p}}\left(\frac{\mathrm{W}}{\mathrm{L}}\right)_{\mathrm{p}}\left(\mathrm{V}_{\mathrm{DD}}-\mathrm{V}_{\text {in }}-\left|\mathrm{V}_{\mathrm{THP}}\right|\right)^{2}\right) \\
& \left|\mathrm{V}_{\text {thp }}\right|=\left|\mathrm{V}_{\text {th } 0 \mathrm{p}}\right|+\gamma\left(\sqrt{2\left|\phi_{\mathrm{f}}\right|-\mathrm{V}_{\mathrm{sb}}}-\sqrt{\left.2\left|\phi_{\mathrm{f}}\right|\right)}\right.
\end{aligned}
$$

Using equation (14) the oscillation frequency will decrease with increasing the control voltage. Also using the bulk voltage a wider tuning range of frequency can be achieved. Equation (15) shows larger $\mathrm{W}$ will result in higher oscillation frequency, but the node capacitance will also increase that limits the maximum achievable frequency.

\section{SIMULATION RESULTS}

The designed RVCO has been simulated using TSMC 180nm technology parameters. The supply voltage is $1.8 \mathrm{~V}$ and the control voltage has been changed from 0 to $1 \mathrm{~V}$. For the proper operation of the RVCO, the overdrive voltage of the NMOS transistors should be kept as low as possible. In this simulation, the over-drive voltage is set to $20 \mathrm{mV}$. When the control voltage is $1 \mathrm{~V}$ the equivalent resistance of the current source is at its maximum and the oscillation frequency will be at its minimum value. The output waveform for $\mathrm{Vc}=0.5 \mathrm{~V}$ has been shown in Figure 8 .

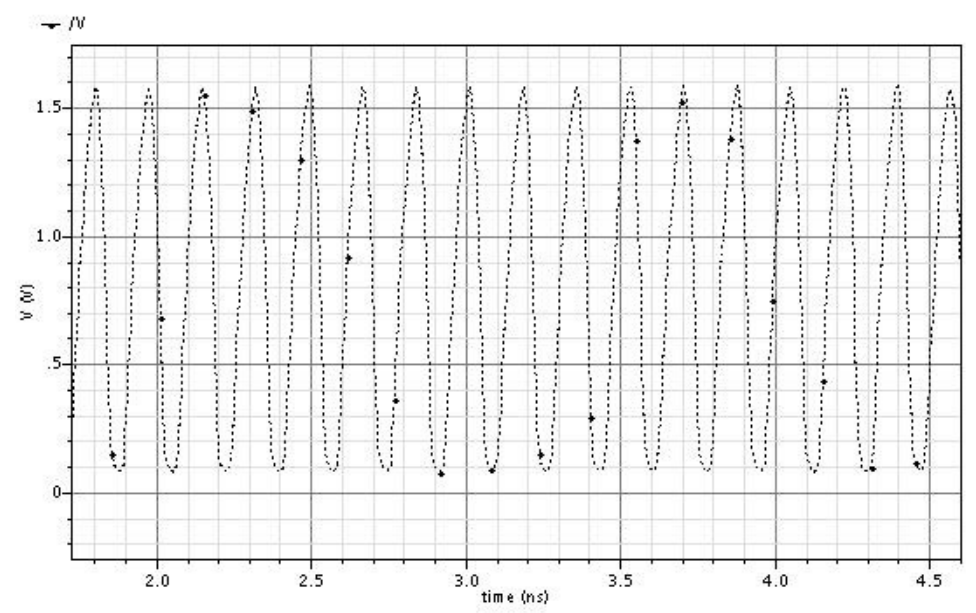

Figure 8. Oscillator output waveform for $\mathrm{Vc}=0.5 \mathrm{~V}$

The oscillation frequency versus control voltage has been plotted in Figure 9. For the control voltage changing from 0 to $1 \mathrm{~V}$ the output frequency changes from $1.75-9.27 \mathrm{GHz}$. 
Electrical and Electronics Engineering: An International Journal (ELELIJ) Vol 3, No 2, May 2014

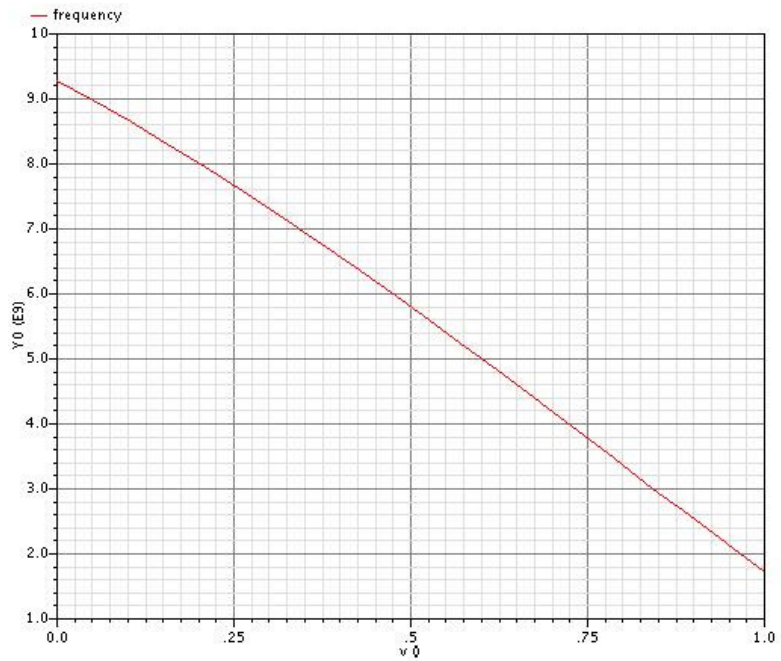

Figure 9. Oscillation frequency versus control voltage

Phase noise is a very important characteristic of a ring VCO. Phase noise is due to noise at the input of the feedback loop that causes the ramp $-20 \mathrm{dBc} / \mathrm{dec}$ and the Flicker noise and thermal transistor is biased that causes the ramp $-30 \mathrm{dBc} / \mathrm{dec}$ in the beginning of the Spectrum [14].

The phase noise of the RVCO has been simulated using SpectreRF as shown in Figure 9. The phase noise for oscillators is defined as in equation (16):

$\mathrm{L}\{\Delta \omega\}=10 \log \left[\frac{2 \mathrm{FkT}}{\mathrm{P}_{\text {sig }}}\left\{1+\left(\frac{\omega_{0}}{2 \mathrm{Q} \Delta \omega}\right)^{2}\right\}\left(1+\frac{\Delta \omega_{1 / \mathrm{f}^{3}}}{\Delta \omega}\right)\right]$

Where $\mathrm{L}\{\Delta \mathrm{w}\}$ is phase noise with $\Delta \omega$ distance from user frequency $\omega_{0}$, Psig is the power of the oscillator output signal, $\mathrm{F}$ is noise figure, $\mathrm{T}$ is absolute temperature, $\mathrm{K}$ is Boltzmann's constant, $\omega_{0}$ is center frequency of the oscillator, $\Delta \omega$ is offset frequency, $\Delta \omega \mathrm{i} / \mathrm{f} 3$ is corner frequency of the device noise and $\mathrm{Q}$ is quality factor.

The above value has been calculated for the designed RVCO. For $\mathrm{Vc}=0.5 \mathrm{~V}$ and offset frequency of $1 \mathrm{MHz}$ the phase noise is equal to $-88.86 \mathrm{dBc} / \mathrm{Hz}$ as shown in Figure 10. 
Electrical and Electronics Engineering: An International Journal (ELELIJ) Vol 3, No 2, May 2014

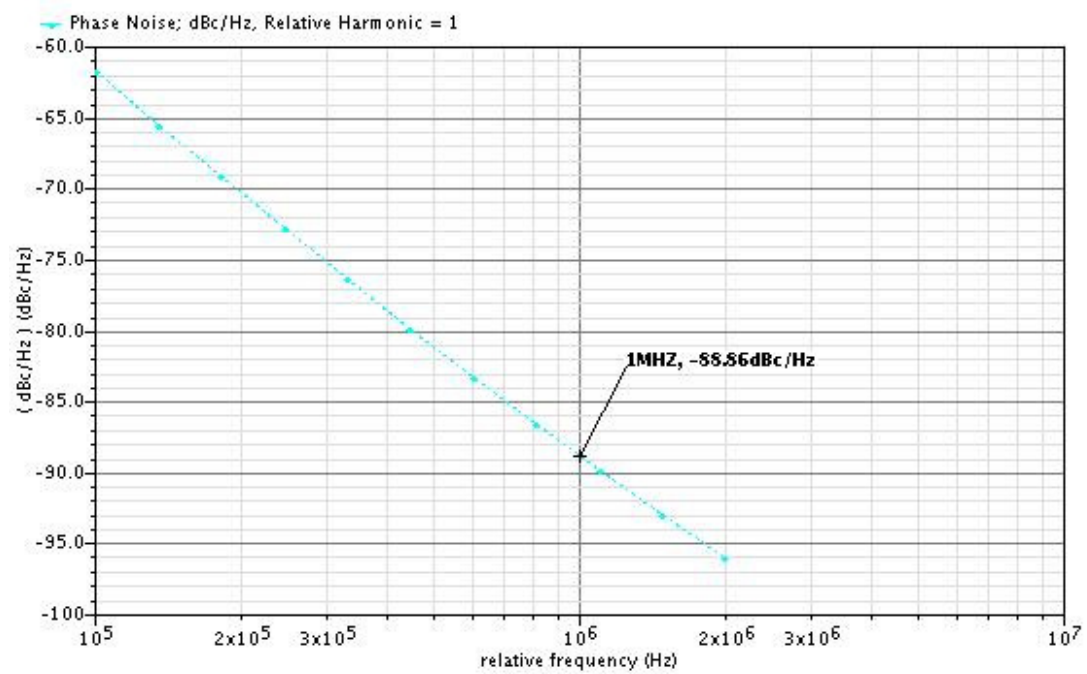

Figure 10. Phase noise performance for $\mathrm{V}_{\mathrm{c}}=0.5 \mathrm{~V}$ and offset frequency of $1 \mathrm{MHz}$

A Figure of Merit (FOM) has been defined for the purpose of comparison of different oscillators as follows [15]:

$\mathrm{FOM}=\mathrm{L}\{\Delta \mathrm{f}\}-20 \log \left(\frac{\mathrm{f}_{\mathrm{OSC}}}{\Delta \mathrm{f}}\right)+10 \log \left(\frac{\mathrm{P}_{\mathrm{mw}}}{1 \mathrm{~mW}}\right)$

Where $\mathrm{f}_{\text {osc }}$ is oscillator frequency, $\mathrm{P}_{\mathrm{mw}} \mathrm{DC}$ power in the oscillation frequency, $\mathrm{L}\{\Delta \mathrm{f}\}$ is the phase noise in offset frequency of $\Delta \mathrm{f}$.

Table 2 is a comparison of this design with other reported papers. A much wider frequency tuning range has been achieved using simultaneous bulk and gate control technique. Furthermore, better phase noise and FOM have been obtained while having reasonable power dissipation.

Table 2. Performance comparison of several ring oscillators

\begin{tabular}{|c|c|c|c|c|c|c|}
\hline REF & $\begin{array}{c}\text { Tech } \\
(\mathbf{u m})\end{array}$ & $\begin{array}{c}\text { Tuning } \\
\text { range(GHz) }\end{array}$ & $\begin{array}{c}\text { Supply } \\
\text { Voltage(v) }\end{array}$ & $\begin{array}{c}\text { Power } \\
(\mathbf{m w})\end{array}$ & $\begin{array}{c}\text { Phase } \\
\text { Noise(dBc/Hz) }\end{array}$ & $\begin{array}{c}\text { FOM } \\
(\mathbf{d B c} / \mathbf{H z})\end{array}$ \\
\hline$[1]$ & 0.18 & $0.479-4.09$ & 1 & 13 & $-93.3 @ 1 \mathrm{MHz}$ & -154.4 \\
\hline$[5]$ & 0.18 & $0.12-1.3$ & 0.5 & 0.085 & $-72 @ 1 \mathrm{MHz}$ & -145 \\
\hline$[10]$ & 0.18 & $3.95-4.15$ & 1.8 & - & - & - \\
\hline$[9]$ & 0.18 & Max5.5 & - & 17.5 & $-104 @ 4 \mathrm{MhHz}$ & -154 \\
\hline$[11]$ & 0.18 & $2.17-4.16$ & 1.8 & 3 & $-97.85 @ 1$ & - \\
\hline$[12]$ & 0.18 & $3.12-5.26$ & 1.8 & 0.625 & - & - \\
\hline$[4]$ & 0.18 & $0.25-2.1$ & $0.8-1.8$ & - & - & - \\
\hline $\begin{array}{c}\text { This } \\
\text { Work }\end{array}$ & 0.18 & $1.73-9.27$ & 1.8 & 5.17 & $-88.86 @ 1 \mathrm{MHz}$ & -156.99 \\
\hline
\end{tabular}




\section{CONCLUSION}

Integrated RVCOs are more immune to noise and have better tuning range than LC counterparts. RVCOs can be used for broad range of applications if their performance is improved by design techniques. In this work a high performance wide tuning range RVCO has been designed using TSMC $180 \mathrm{~nm}$ technology. A new approach has been used to control the current source in the RVCO to achieve a wide adjustable range. As a result high tuning range RVCO has been simulated. Body biasing technique has been used to adjust transistor threshold voltage continuously. By using gate and bulk voltage simultaneously wider oscillation frequency has been achieved while keeping phase noise and power dissipation low. The RVCO has 1.73-9.27 GHz linear frequency range with the control voltage $0-1 \mathrm{~V}$. The phase noise for $\mathrm{V}_{\mathrm{c}}=0.5$ with offset frequency of $1 \mathrm{MHz}$ is $-88.86(\mathrm{dBc} / \mathrm{Hz})$.

\section{REFERENCES}

[1] M.-L. Sheu, Y.-S. Tiao, L.-J. Taso, "A 1-V 4-GHz wide tuning range voltage-controlled ring oscillator in 0.18um CMOS," Microelectronics Journal, vol. 42, pp. 897-902, 2011.

[2] J. Zhao and Y.-B. Kim, "A low-power digitally controlled oscillator for all digital phase-locked loops," VLSI Design, vol. 2010, p. 2, 2010.

[3] W.-H. Lee, B.-J. Gu, Y. Nishida, H. Takao, K. Sawada, M. Ishida, "Oscillation-controlled CMOS ring oscillator for wireless sensor systems," Microelectronics Journal, vol. 41, pp. 815-819, 2010.

[4] M. Frankiewicz and A. Kos, "Wide-frequency-range low-power variable-length ring oscillator in UMC CMOS $0.18 \mu \mathrm{m}, "$ in Mixed Design of Integrated Circuits and Systems (MIXDES), 2013 Proceedings of the 20th International Conference, 2013, pp. 291-293.

[5] T. Li, B. Ye, J. Jiang, "0.5 V 1.3 GHz voltage controlled ring oscillator," in ASIC, 2009. ASICON'09. IEEE 8th International Conference on, 2009, pp. 1181-1184.

[6] U. Guler and G. Dundar, "Modeling CMOS Ring Oscillator Performance as a Randomness Source," IEEE Transactions on Circuits and Systems I: Regular Papers, vol. 61, pp. 712- 724, 2014.

[7] T. V. Cao, D.T. Wisland, T.S. Lande, F. Moradi, "A bulk-controlled ring-VCO with 1/f-noise reduction for frequency $\Delta \Sigma$ modulator," in Mixed Design of Integrated Circuits \& Systems, 2009. MIXDES'09. MIXDES-16th International Conference, 2009, pp. 187-192.

[8] A. Ramazani, S. Biabani, GH. Hadidi, "CMOS Ring Oscillator with Combined Delay Stages," AEUInternational Journal of Electronics and Communications, 2014.

[9] P. Nugroho, R.K. Pokharel, H. Kanaya, K. Yoshida, "A 5.9 GHz Low Power and Wide Tuning Range CMOS Current-controlled Ring Oscillator," International Journal of Electrical and Computer Engineering (IJECE), vol. 2, pp. 293-300, 2012.

[10] J. Radic, A. Djugova, L. Nagy, M. Videnovic-Misic, "Body effect influence on $0.18 \mu \mathrm{m}$ CMOS ring oscillator performance for IR-UWB pulse generator applications," in Embedded Computing (MECO), 2012 Mediterranean Conference on, 2012, pp. 170-173.

[11] J. Garg and S. Verma, "Design of low power Voltage Controlled Oscillator," in Emerging Technology Trends in Electronics, Communication and Networking (ET2ECN), 2012 1st International Conference on, 2012, pp. 1-4.

[12] R. Ashish, J.N. Vashishtha, R K sarin, "A RF Low Power 0.18- $\mu$ m based CMOS Differential ring oscillator," Proceedings of the World Congress on Engineering, vol. 2, 2012.

[13] S.-M. Kang and Y. Leblebici, CMOS digital integrated circuits: Tata McGraw-Hill Education, 2003.

[14] A. Daghighi and A. Neshat-Niko, "VCO Design and Simulation Using TSMC 0.18 um Process to Meet IEEE802.11a Requirements," Majlesi Journal of Electrical Engineering, vol. 2, pp. 29-37, 2008.

[15] S. Shieh Ali Saleh and N. Masoumi, "Wide-tuning-range, low-phase-noise quadrature ring oscillator exploiting a novel noise canceling technique," AEU - International Journal of Electronics and Communications, vol. 66, pp. 372-379, 2012. 